\title{
Zur zweiten Auflage
}

Die zweite Auflage des Handbuchs liegt nunmehr in einer erweiterten und verbesserten Ausgabe vor. Eingearbeitet sind in den letzten Jahren erschienene Studien sowie weitere Informationen zur Geschichte der Märchensammlung der Brüder Grimm und zur Überlieferungs- und Textgeschichte einzelner Märchen.

Göttingen, 13. Januar 2013

\section{Zur dritten Auflage}

Die in den letzten Jahren erschienenen Studien zu den Kinder- und Hausmärchen der Brüder Grimm haben zu einer Reihe neuer Erkenntnisse geführt, die in dieser ergänzten und überarbeiteten dritten Auflage berücksichtigt worden sind. Zusätzlich zu den internationalen Erzähltypen und -motiven (ATU; Mot.) finden sich nun nach Vorliegen des deutschen Typenkatalogs (DMK/Uther) auch die betreffenden Angaben zu Erzähltypen der früheren und heutigen deutschsprachigen Gebiete. Daraus geht auch hervor, in welchem hohen Maße die Brüder Grimm nachfolgende Sammler und Herausgeber von Volkserzählungen beeinflußt haben. Nicht wenige Stücke der Brüder Grimm wirken als Leitfassungen nach und haben ältere und zeitgenössische Überlieferungen verdrängt.

Göttingen, 20. Juli 2021 